\title{
THE ANALYSIS OF LATE BRONZE AGE GLASS FROM NUZI AND THE QUESTION OF THE ORIGIN OF GLASS-MAKING*
}

\author{
A. J. SHORTLAND $\dagger$ and S. KIRK \\ Cranfield Forensic Institute, Cranfield University, Defence Academy of the United Kingdom, Shrivenham \\ SN6 8LA, UK \\ K. EREMIN \\ Harvard Art Museums, 32 Quincy Street, Cambridge, MA 02138, USA \\ P. DEGRYSE \\ Earth and Environmental Sciences, Geology, Centre for Archaeological Sciences Celestijnenlaan 200E, \\ b2408, BE-3001 Leuven, Belgium \\ and M. WALTON
}

Center for Scientific Studies in the Arts, Northwestern University, 2145 Sheridan Road, Tech K111,

Evanston, Il 60208, USA

\begin{abstract}
This paper re-analyses a considerable corpus of glass from the Late Bronze Age site of Nuzi, found near Kirkuk in Iraq. SEM-WDS and Sr and Nd isotopic analysis were applied, in addition to cataloguing the glass. The work showed that the glass technology at Nuzi was subtly different from contemporary Egyptian sites, using different ways of opacifying and working glass. At least two, perhaps three, Near Eastern production sites are postulated. The range of glass colours and the skill of their application at Nuzi was perhaps not on a par with the Egyptian sites. This led to a reconsideration and review of the accepted wisdom that the Near East is the source of the innovation that is glass-making. This opinion is based on limited textual and iconographic sources and is dominated by an erroneous early date for a very developed Nuzi glass industry along with a few finds of glass vessels in early contexts. Some of this evidence has now been at least questioned, suggesting that glass-making in Egypt, at least as early as the middle of the 15th century $B C$, and probably earlier, is no later than that in the Near East. It is argued that it is far from clear that the Near East was the source of the innovation and that a more cautious approach would better fit the evidence.
\end{abstract}

KEYWORDS: LATE BRONZE AGE, GLASS, NUZI, NEAR EAST, ISOTOPIC ANALYSIS, SEM-WDS

\section{INTRODUCTION}

Man-made glass first occurs in quantity in the Late Bronze Age, in around 1500 BC. In this period, it is made from heating quartz pebbles and a flux, in this case the ashes of desert or coastal plants, to over $1000{ }^{\circ} \mathrm{C}$ so that they fuse and melt (Turner 1954, 1956). Almost all the glass is coloured and often opaque, and a range of colouring elements, including cobalt, copper, manganese, lead and antimony, were used (Kaczmarczyk and Hedges 1983). Actual production sites are rare. In the earliest period, in the middle of the 14th century BC, two are known from Egypt (Amarna and Malkata), with one probably slightly later site at Qantir (Keller 1983; Nicholson 2007; Pusch and Rehren 2007). However, in the Near East there are no known production centres, although it is widely believed from compositional evidence that glass

\footnotetext{
*Received 22 April 2017; accepted 19 May 2017

†Correspondence: email A.shortland@cranfield.ac.uk

(C) 2017 University of Oxford
} 
was being produced here, probably at several different workshops (Shortland 2012; Walton et al. 2012).

Nuzi was a Late Bronze Age (LBA) city on the site of Yorghan Tepe, near Kirkuk in Northern Iraq. 'Nuzi' was the Late Bronze Age name that was given to the city and was identified as such from amongst 5000 or so clay tablets recovered from the site in a series of excavations from 1925 to 1931, first by the American Society for Oriental Research (ASOR) and subsequently by Harvard University. These were directed initially by Edward Chiera, and the last two seasons by Richard Starr (Starr 1939). A large proportion of this relatively small city was uncovered and the finds were split between the excavators and the Baghdad Museum. Most of the finds that left Iraq are now in the Semitic Museum at Harvard University, with smaller numbers in other museums at Harvard and the University of Pennsylvania (Vandiver 1983). Amongst these finds are large amounts of glass, perhaps the largest to be recovered from a single site in the Near East, and rivalling the quantities from the Late Bronze Age Egyptian sites of Amarna and Malkata (Starr 1939; Vandiver 1983). The glass finds are concentrated in Stratum II, related to the Mittani Period, a destruction layer that stretches over much of the city, the date for which is discussed below. However, a Sasanian settlement covered parts of the site and there are also later Islamic graves present, both of which make the stratigraphy more complex.

This paper presents the results of a new and extensive study of glass from Nuzi, which is part of a long-term international re-examination of the material culture from Nuzi in general (Shortland et al. 2008). It combines the examination of the objects with a survey of their find sites and contexts alongside new analyses of the materials (in this paper, the glass) by a variety of techniques, in this case microprobe and $\mathrm{Sr}$ and $\mathrm{Nd}$ isotopes. The details of the glasses analysed, all from the Harvard Semitic Museum, Harvard University, are shown in Tables 1 and 2 below. This shows the glass of Nuzi in a new light, and enables clearer comparison with contemporary Egyptian glass and glass-making. Finally, the relationships between the Near East and Egypt and the production of the very first glass are considered.

\section{METHODOLOGY}

Samples were mounted in resin blocks, polished flat and carbon coated. The SEM-WDS microprobe used was a Cameca SX100 based at the Natural History Museum, London. This was calibrated for $\mathrm{Si}, \mathrm{Al}, \mathrm{Ca}, \mathrm{Mg}, \mathrm{Na}, \mathrm{K}, \mathrm{Fe}, \mathrm{Ti}, \mathrm{Co} \mathrm{Cu}, \mathrm{Mn}, \mathrm{Ni}, \mathrm{Zn}, \mathrm{Sn}, \mathrm{Sb}, \mathrm{Ba}, \mathrm{Pb} \mathrm{Cr}, \mathrm{P}, \mathrm{S}$, $\mathrm{Cl}$ and $\mathrm{Sr}$, following techniques very similar to earlier studies (Henderson 1988; Shortland and Eremin 2006). The elements were assigned to the five spectrometers and each element calibrated against conventional WDS standards (for a list, see Kirk 2009, app. 1). The accelerating voltage was $20 \mathrm{kV}$ and the spot size $20 \mu \mathrm{m}$. These were optimal to allow all elements to be measured, while avoiding the soda migration that can be a problem with smaller spots and higher $\mathrm{kV}$. The detection limits of the runs are given in Kirk (2009, app. A, table a), but mostly average 200-500 ppm for these elements, the best being $\mathrm{Mg}$ (101 ppm on average) and Al (94 ppm) and the worst $\mathrm{Zn}(795 \mathrm{ppm})$ and Fe (551 ppm).

For $\mathrm{Sr}-\mathrm{Nd}$ isotopic analysis, $100 \mathrm{mg}$ of powdered sample was weighed into a Savillex screwtop beaker and digested in a 3:1 mixture of $22 \mathrm{M} \mathrm{HF}$ and $14 \mathrm{M} \mathrm{HNO}_{3}$ on a hot plate. The digest thus obtained was dried and the residue re-dissolved in aqua regia. After digestion was completed, the sample was evaporated to near dryness and the residue was taken up into $7 \mathrm{M}$ $\mathrm{HNO}_{3}$. The concentrations of $\mathrm{Sr}$ and $\mathrm{Nd}$ were determined using a quadrupole-based PerkinElmer SCIEX Elan 5000 ICP-MS instrument. An internal standard (In) was used to correct for matrix 


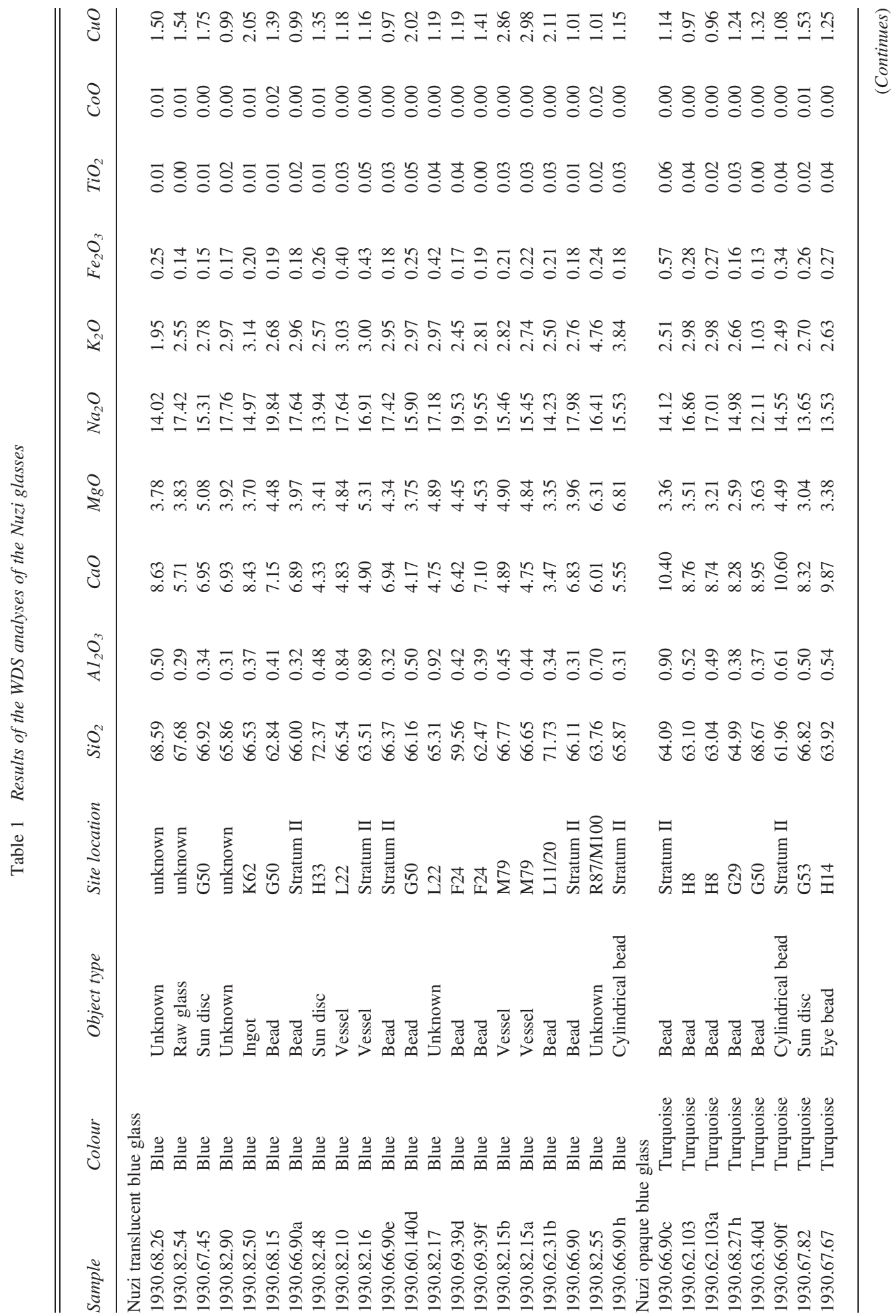




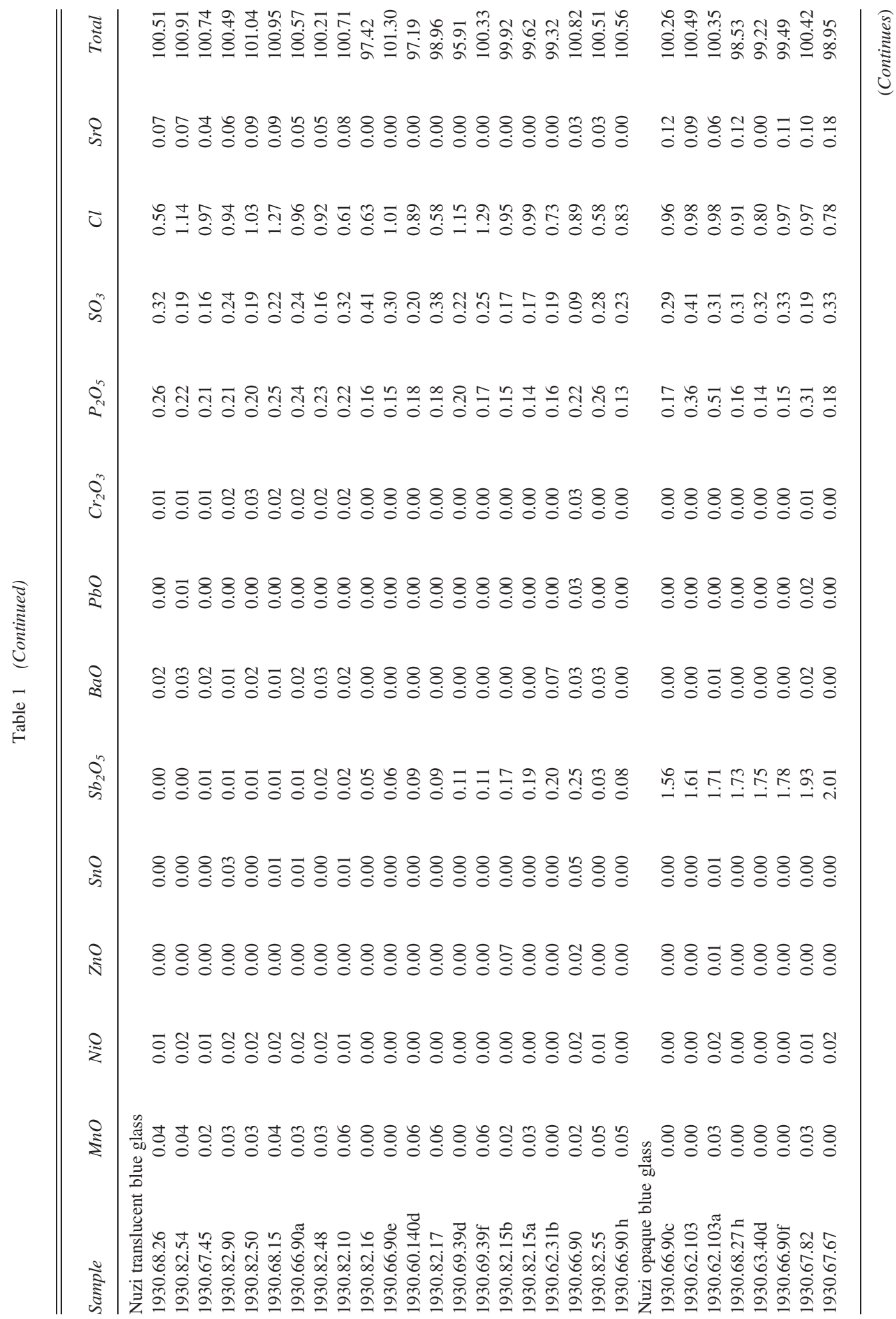




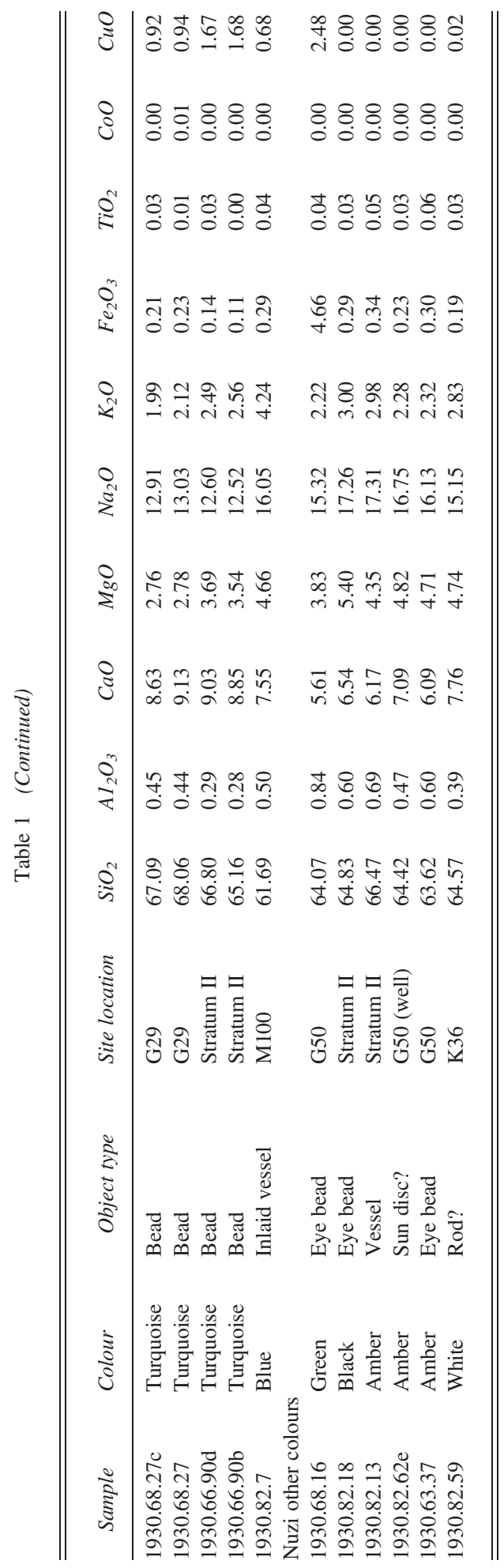




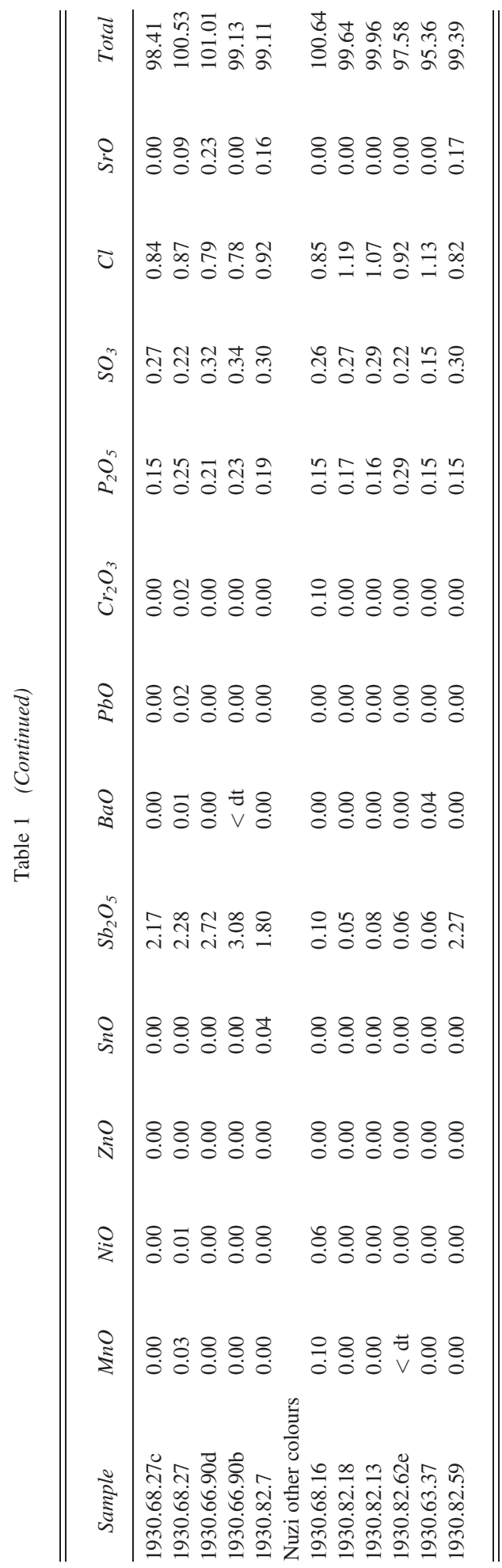


A. J. Shortland et al.

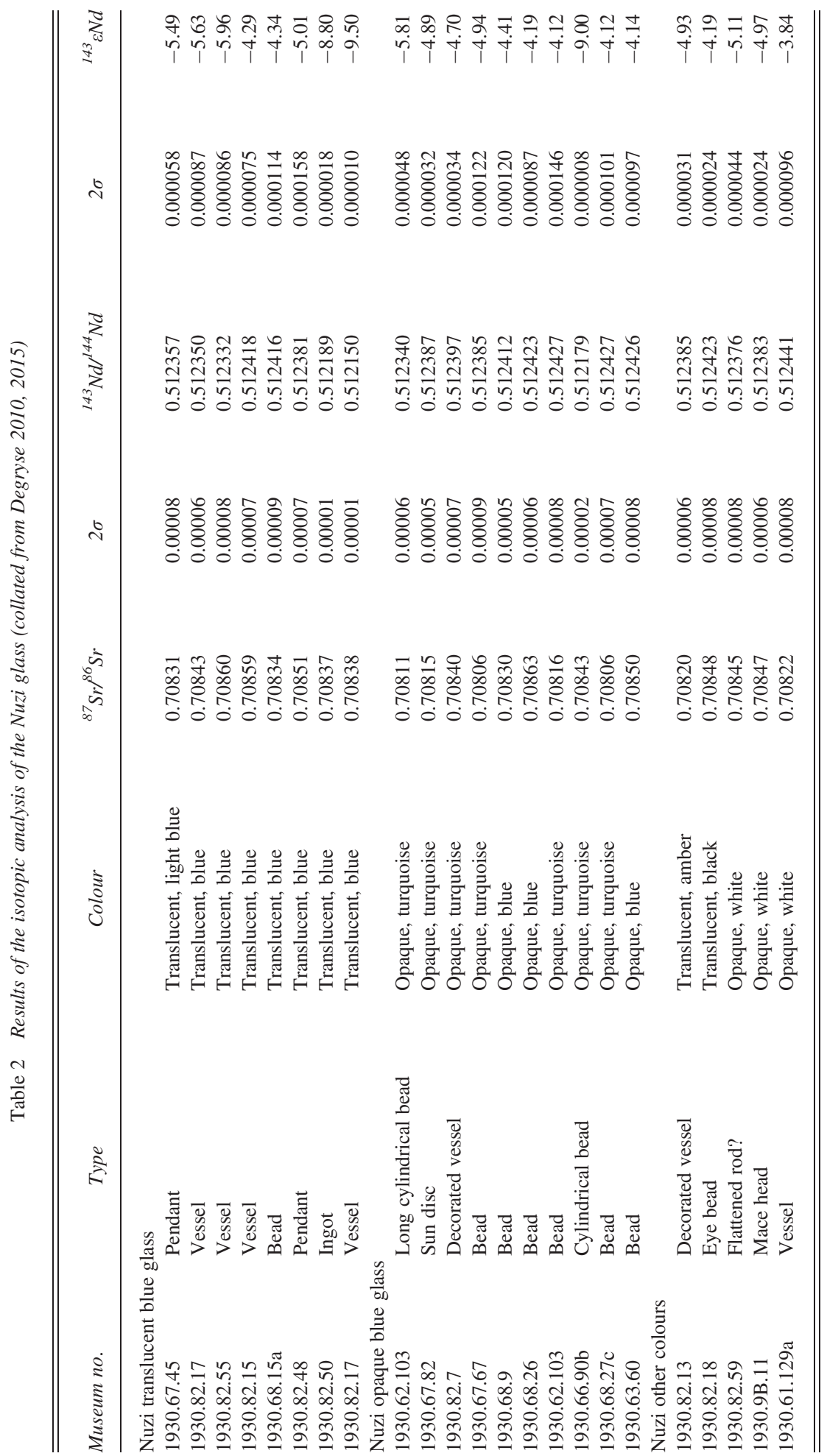


effects, signal drift and instrument instability, and calibration was performed against an external standard containing known amounts of the elements to be determined.

After digestion, chromatographic isolation of $\mathrm{Sr}$ and $\mathrm{Nd}$ was performed prior to isotopic analysis. Sr and $\mathrm{Nd}$ ratios for samples 1930.82.17, 1930.82.50 and 1930.66.90b from Nuzi were determined using a six-collector Finnigan Mat 262 thermal ionization mass spectrometer (TIMS), running in multi-collection mode. Sr isotope ratios were normalized to ${ }^{86} \mathrm{Sr} /{ }^{88} \mathrm{Sr}=0.1194$, and $\mathrm{Nd}$ isotope ratios to ${ }^{146} \mathrm{Nd} /{ }^{144} \mathrm{Nd}=0.7219$. Repeated static measurements of the NIST SRM 987 isotopic reference material over the duration of the study yielded an average ${ }^{87} \mathrm{Sr} /{ }^{86} \mathrm{Sr}$ ratio of $0.71025 \pm 0.00002$. Repeated measurements of the La Jolla $\mathrm{Nd}$ standard yielded ${ }^{143} \mathrm{Nd} /{ }^{144} \mathrm{Nd}=0.511848 \pm 0.000009$. In this case, $\mathrm{Sr}$ and $\mathrm{Nd}$ isolation was carried out using the protocol developed by Pin et al. (1994), using coupled miniaturized Teflon columns containing $50 \mathrm{ml}$ of Eichrom Sr Spec and TRU Spec resin, respectively. Matrix components were removed from the resin using $2 \mathrm{M} \mathrm{HNO}_{3}$, while $\mathrm{Sr}$ and the REE were eluted with deionized $\mathrm{H}_{2} \mathrm{O}$. For the isolation of $\mathrm{Nd}$, the REE cut was further passed through a column containing $2 \mathrm{ml}$ of Eichrom $\mathrm{Ln}$ Spec resin. This resin was washed with $5.5 \mathrm{ml}$ of $0.25 \mathrm{M} \mathrm{HCl}$ after adding the sample, after which $\mathrm{Nd}$ was stripped off using $4 \mathrm{ml}$ of $0.25 \mathrm{M} \mathrm{HCl}$.

$\mathrm{Sr}$ and $\mathrm{Nd}$ isotope ratios for all other samples from Nuzi were obtained with a Thermo Scientific Neptune multi-collector inductively coupled plasma - mass spectrometer (MC-ICP-MS), equipped with a micro-flow PFA-50 Teflon nebulizer and a double spray chamber, consisting of a cyclonic and a Scott-type sub-unit for sample introduction, and running in static multicollection mode. A concentration-matched solution of NIST SRM $987 \mathrm{SrCO}_{3}$ isotopic reference material was used as an external standard $\left({ }^{86} \mathrm{Sr} /{ }^{88} \mathrm{Sr}=0.1194\right)$ to correct for instrumental mass discrimination (sample-standard bracketing). To correct for the interference from $\mathrm{Kr}$ at an $\mathrm{m} / \mathrm{z}$, ratio of 86 , the intensity obtained for ${ }^{83} \mathrm{Kr}$ was used. On average, ${ }^{87} \mathrm{Sr} /{ }^{86} \mathrm{Sr}$ isotope ratios were measured with an internal precision $(2 \mathrm{~s})$ of 0.000044 . For $\mathrm{Nd}$, instrumental mass discrimination correction was performed using JNdi-1 reference material (Geological Survey of Japan, $\left.{ }^{143} \mathrm{Nd} /{ }^{144} \mathrm{Nd}=0.51515,{ }^{146} \mathrm{Nd} /{ }^{144} \mathrm{Nd}=0.7219\right)$. The intensity obtained for ${ }^{147} \mathrm{Sm}$ was used to correct the intensities obtained at $\mathrm{m} / \mathrm{z} 144$ for spectral interference from Sm. On average, ${ }^{143} \mathrm{Nd} /{ }^{144} \mathrm{Nd}$ isotope ratios were measured with an internal precision $(2 \mathrm{~s})$ of $0.000022 . \mathrm{Sr}$ isolation (De Muynck et al. 2009) was accomplished using a BioSpin column (BioRad) packed with $400 \mathrm{ml}$ of $\mathrm{Sr}$ spec resin (Eichrom). After loading the resin with $0.1 \mathrm{ml}$ of solution in $7 \mathrm{M}$ $\mathrm{HNO}_{3}$, rinsing it with $4 \mathrm{ml}$ of $7 \mathrm{M} \mathrm{HNO}_{3}$ eliminated the matrix. Subsequently, the Sr fraction was eluted with $5.5 \mathrm{ml}$ of $0.05 \mathrm{M} \mathrm{HNO}_{3}$. The isolation of $\mathrm{Nd}$ involved a two-step chromatographic separation (Ganio et al. 2012). The sample, taken up in $1 \mathrm{ml}$ of $2 \mathrm{M} \mathrm{HNO}_{3}$, was loaded on to a Micro-BioSpin column (BioRad), filled with $600 \mathrm{ml}$ of TRU Spec resin (Eichrom). The resin was first washed with $4 \mathrm{ml}$ of $2 \mathrm{M} \mathrm{HNO}_{3}$, after which the Micro-BioSpin column was connected to an Eichrom column $(0.8 \mathrm{~cm}$ inner diameter) packed with $1.5 \mathrm{ml}$ of $\mathrm{Ln}$ Spec resin (Eichrom). Rinsing with $7 \mathrm{ml}$ of $0.05 \mathrm{M} \mathrm{HNO}_{3}$ transferred the LREE (light rare earth elements) fraction from the TRU Spec resin into the Ln Spec resin. The Ln Spec resin was then washed with $5 \mathrm{ml}$ of $0.25 \mathrm{M} \mathrm{HCl}$, after which the $\mathrm{Nd}$ fraction was stripped off using $9 \mathrm{ml}$ of $0.25 \mathrm{M} \mathrm{HCl}$.

\section{RESULTS}

\section{Survey}

A survey of the vitreous materials from the site of Nuzi was carried out to reveal the number and extent of the vitreous assemblage (Kirk 2009). Starr estimated that there were 16000 beads of 
vitreous materials recovered from the temple complex of Nuzi alone (Starr 1939, 94). Somewhere around 10000 are recorded in the site finds books (Kirk 2009, 78-81). The Harvard Semitic Museum currently houses around 5000 beads in its collection. These beads are of various vitreous materials, including glass, faience and Egyptian blue. Glass vessels are rarer, with around 30 vessels represented in the Harvard collection, although the number of fragments is higher at 133. Six or seven pendants and around three fragments of raw glass were also recovered. Kirk (2009) considers in detail the distribution of the vitreous materials at Nuzi and their spread across the site. In terms of colour, the Nuzi glass assemblage is overwhelmingly blue-well over 90\%. It is far less well preserved than at Egyptian sites in general-the damp environment has seriously degraded the glass, often to the extent of reducing it to a white powder that is very different from the original material.

Starr attempted to document the various colours of glass found and relate these to object typologies. However, the colour terms used are somewhat confusing, as he refers throughout to the dominance of 'green' glass while stating that this was originally a deep blue, which weathers to green and then white. Hence, throughout the publication, the references to green glass in fact refer to an original blue glass and in this survey, only one unweathered (i.e., original) green glass was found within vessels or beads (eye bead 1930.68.16; see Table 1). Blue glass was overwhelmingly the most common for both beads and vessels. In vessels, the other colours-white, yellow and 'black', in decreasing order of frequency-were used mainly as inlays on the (originally) blue glass. Among the bead assemblage, Starr noted that some smaller zooform beads were made of white glass and some small spherical beads were made of yellow glass (now in poor condition) with rare black glass pendants and small glass beads (Starr 1939, 446).

Starr stressed that for the vessel glass 'the number of original colours is more limited than a casual investigation of the specimens would suggest, for the different conditions of burial have had a great and confusing effect on different specimens' (Starr 1939, 458). Despite an apparent diversity of colours, an original blue glass was used for the vessel body in all but one instance (a yellow vessel body inlaid with darker yellow and orange). As with beads, the frequency of use of the non-blue glass appeared to be white, yellow, orange and black, in decreasing order. Yellow and orange were described as ranging from brilliant colours to tan and brick-red respectively and probably originate from the same initial yellow-orange glass (Starr 1939, 458). A common origin for the yellow and orange was also implied by Vandiver 1983, who states that 'Starr ranked the colours of glass vessels in order of frequency of use as follows: blue, white, yellow-orange to brick-red, and black'. Black glass was also altered, ranging from light grey to true black.

The polychrome beads from Nuzi have been the subject of previous study (Vandiver 1983). However, it should be noted that many of the polychrome beads that were thought in the past to be either doubtful or to belong to LBA Nuzi have now been firmly reclassified as later (Eremin et al. in prep.). These glasses have the high potash and magnesia typical of plant ash glasses, but have higher alumina (1.2-2.2\%; see Eremin et al. in prep.), which is typical of a glass made with sand, containing as it does a significant feldspar component. In addition, many of them are coloured with lead stannate, a later colouring technology. These glasses should therefore be classified as later, as either Islamic or Sasanian glasses, consistent with other glass found elsewhere on the site and published in other studies. Similar arguments can be used for some of the monochrome glasses - once again they are consistent with Sasanian or later glasses, but not LBA. Starr himself, in a video interview shot many years after the excavation and now stored in the Harvard Semitic Museum, explained part of the cause of the problem. He says that workers on the site were rewarded for handing over finds, presumably in an attempt to make sure that none 
of the finds were kept and sold on privately. However, this has had an unintended consequencethe workers found finds, perhaps especially beads, elsewhere and claimed that they had been found in the excavation. Hence the Semitic Museum collection contains many beads that are obviously modern and regarded by all as such. Other items found elsewhere on the site may well have been 'rediscovered' in more interesting and rewarding contexts. This is discussed at length in Eremin et al. (in prep.), which identifies many later beads and glasses that were originally classified as LBA. Small fragments of glass that cannot be confidently classified as LBA by object type and have unusual compositions are therefore discussed in the Eremin paper, rather than here.

It has been stated before that there are little or no remains of glass-working at Nuzi (Shortland et al. 2008). However, the survey of the collection has brought tantalising glimpses that there may be some signs that this was going on. Vandiver (1983) pointed to glass beads wound around copper rods - the intermediary for the manufacture of glass beads. These can still be identified within the assemblage at Harvard, with somewhat deteriorated glass threads around thin copper rods. Some chunks of raw glass (e.g., 1930.82.54) have also been identified in the current study. In addition, the re-examination of finds found two more pieces of evidence for glass-working. The first is a reinterpretation of one of the glass chunks, 1930.82 .50 (Fig. 1 (a)). This is one of the largest fragments, being around $55 \mathrm{~mm}$ across at its widest point and roughly block shaped. However, it has a very clear curved face, which appears to be the impression left on the glass by solidification in a cylindrical ceramic vessel. While difficult to be precise, the curvature of the block suggests a vessel around $170 \mathrm{~mm}$ in diameter, which is similar to those seen in the 'Ingot moulds' from Amarna (Nicholson et al. 1997) and the glass ingots from Ulu Burun. This therefore appears to be part of a glass ingot. Secondly, the collections contain a few (fragmentary) moulds used for making Ishtar figurines, which occur in the overall assemblage fairly commonly in clay and more rarely in glass. One of these mould fragments (1930.8.5) has glass preserved in it (Fig. 1 (b)), showing that it was used to make glass figurines rather than clay ones, presumably on site. These scattered and rare finds and observations start to suggest that there was indeed limited glass-working going on at Nuzi.

(a)

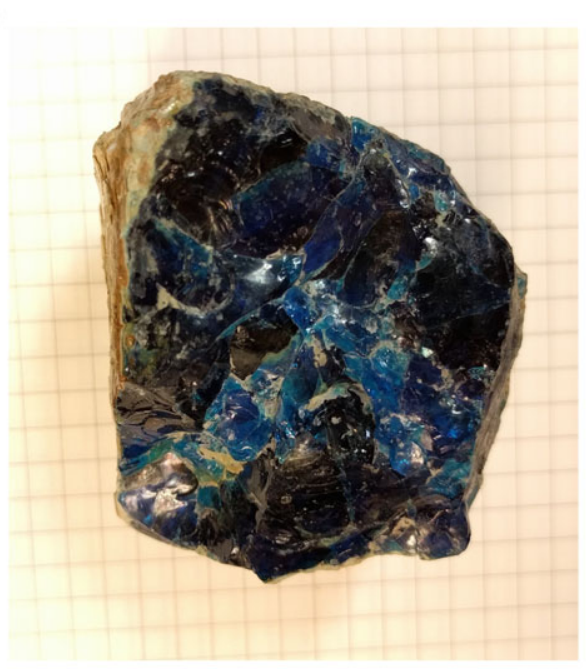

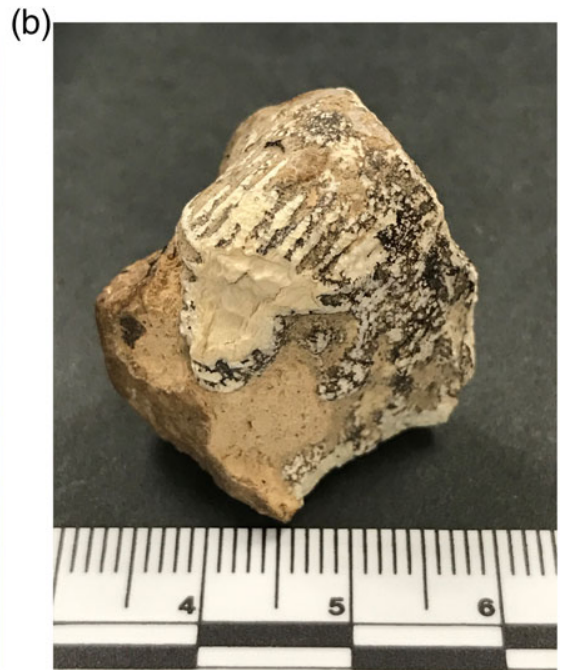

Figure 1 (a) A fragment of an ingot (1930.82.50), about $55 \mathrm{~mm}$ across at its widest point. (b) A weathered-glass Ishtar figurine head, still in a fragment of clay mould (1930.8.5). [Colour figure can be viewed at wileyonlinelibrary.com] 


\section{WDS analyses}

The results of the WDS analyses are shown in Table 1. The blue glasses can be split into two very distinct main groups. The opaque turquoise blue glasses contain between $1.5 \%$ and $3.1 \% \mathrm{Sb}_{2} \mathrm{O}_{5}$, as does the one white glass with good preservation. All the translucent blue glasses and all the other colours contain less than $0.3 \% \mathrm{Sb}_{2} \mathrm{O}_{5}$ (see Fig. 2). Most of the translucent blue glasses have low alumina, less than $1.0 \% \mathrm{Al}_{2} \mathrm{O}_{3}$. The two main groups of blue glasses, one opaque and one translucent, have very strong correlations for alumina and iron (Fig. 3). Not only are they strongly correlated within each group, but the two groups are also subtly different, with the opaque blues having a slightly higher iron to alumina ratio, revealed in different slopes on the correlation plot shown in Figure 3. Six non-blue glasses (one white, one greenish, one black and three amber glasses) appear to lie with the main translucent or opaque blue group, although it is difficult to tell which trend they follow.

In terms of colourants, the LBA assemblage is extremely limited. All the blue glasses are coloured with copper; none show significant concentrations of cobalt. The single white glass, as mentioned above, is coloured by the addition of antimony. The three amber-coloured glasses and the black glass from the Stratum II eye bead lack apparent additional colouring elements. The only other non-blue LBA glass present is a green eye bead (1930.68.16) coloured with copper and iron.

\section{Isotope results}

The isotopic results are shown in Table 2 and Figure 4. They are plotted against data that has been published elsewhere for Malkata in Egypt, Tell Brak and Nippur (Degryse et al. 2010, 2015; Henderson et al. 2010). The great majority of the data have $\varepsilon N d$ values of between -3 and -7 and an ${ }^{87} \mathrm{Sr} /{ }^{86} \mathrm{Sr}$ ratio of $0.7080-0.7086$. There are two groups that lie outside these

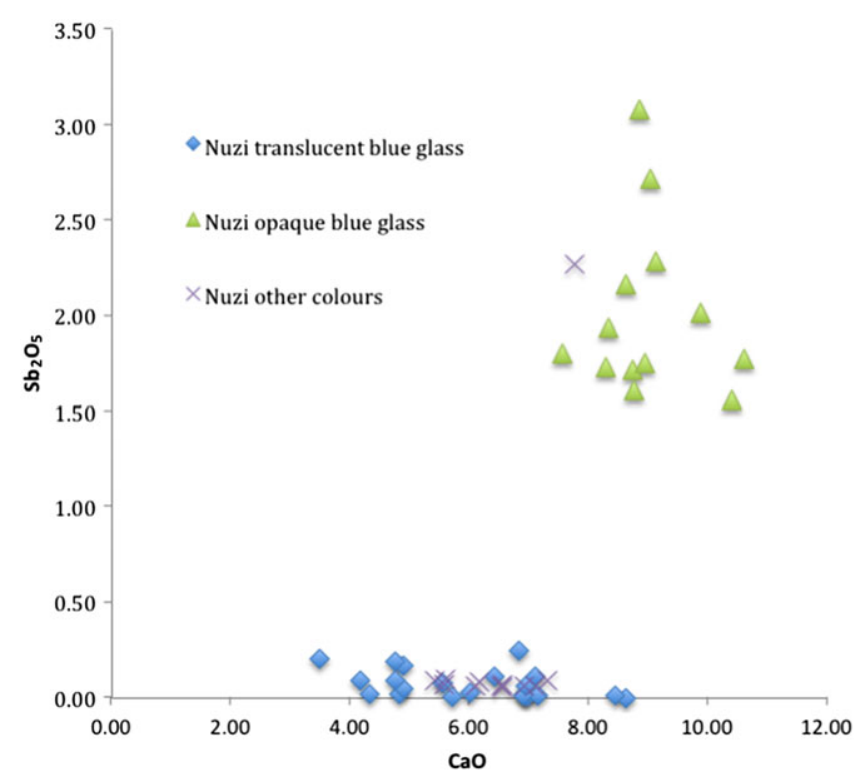

Figure 2 Analyses of Nuzi glass by $\mathrm{SEM}-\mathrm{WDS}$, showing $\mathrm{Sb}_{2} \mathrm{O}_{5}$ against $\mathrm{CaO}$. [Colour figure can be viewed at wileyonlinelibrary.com] 


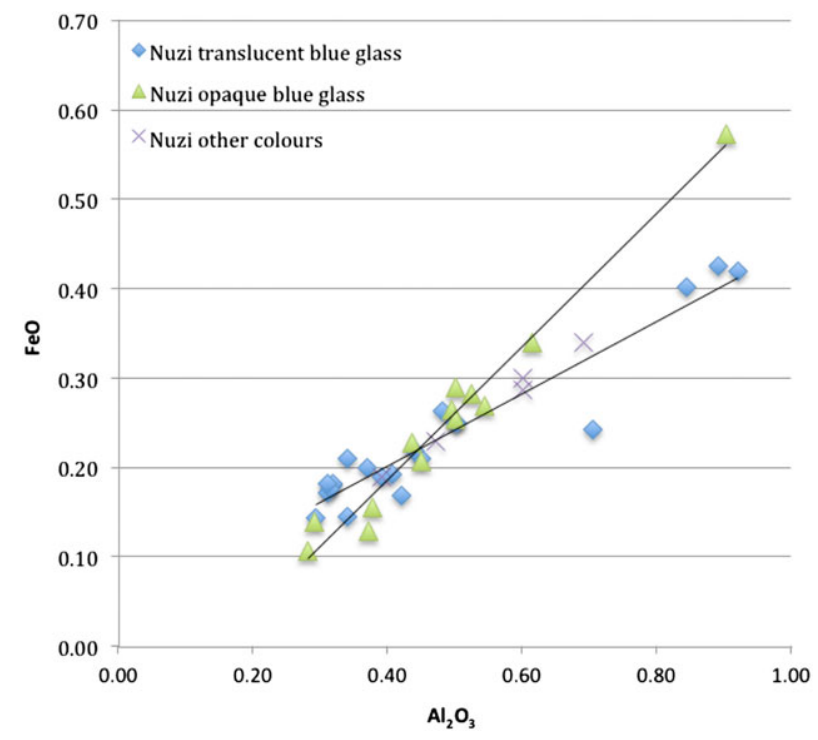

Figure 3 Analyses of Nuzi glass by SEM-WDS, showing $\mathrm{FeO}$ against $\mathrm{Al}_{2} \mathrm{O}_{3}$. [Colour figure can be viewed at wileyonlinelibrary.com]

values: the glasses found in Egypt $\left(\varepsilon N d \approx-9\right.$, and lower $\left.{ }^{87} \mathrm{Sr} /{ }^{86} \mathrm{Sr}\right)$ and a group of four Nuzi samples and one Tell Brak sample also with $\varepsilon N d \approx-9$, but with a ${ }^{87} \mathrm{Sr} /{ }^{86} \mathrm{Sr}$ ratio within the range of the main Nuzi group.

\section{DISCUSSION}

It is fruitful to compare the general distribution, use and technology of the glass at Nuzi with those of the contemporaneous Egyptian sites, especially Amarna, which have been extensively studied. Unusually for Egyptian material, Amarna is an settlement site, and so in that way is comparable to Nuzi. It should be noted, however, that Amarna was a capital city with a court and major temples, albeit short-lived, whereas Nuzi was a provincial town. Nuzi has a very large number of beads, but lesser quantities of vessels, whereas Amarna is very much the opposite. Not only are the distribution of object types different between Nuzi and contemporary Egyptian sites, but the use of colour and glass-working is also subtly different. As mentioned above, the glass found at Nuzi is overwhelmingly blue-either a translucent blue or opaque turquoise. Both of these colours use copper as the main colourant. There are rare finds of yellow, white, green and black glasses. The glass is almost all monochrome. The finds of polychrome beads have been questioned, and are now thought to have very significant numbers of later intrusive material. Indeed, as discussed above, the finds from Nuzi stored in the Semitic Museum contain significant numbers of modern beads, which appear to have become mixed up with LBA and Iron Age beads at some point in the excavation, shipping or storage (Kirk 2009). The simple and often poorly preserved polychrome eye beads present in some numbers and the rare finds of glass vessels are about the only polychrome material that can confidently be ascribed to LBA Nuzi. The more complex and better-preserved polychrome beads all appear to be later.

A study of the fragments of LBA glass does show some very interesting points in the way they are worked. LBA glass vessels are almost always polychrome, and the most common decorative 


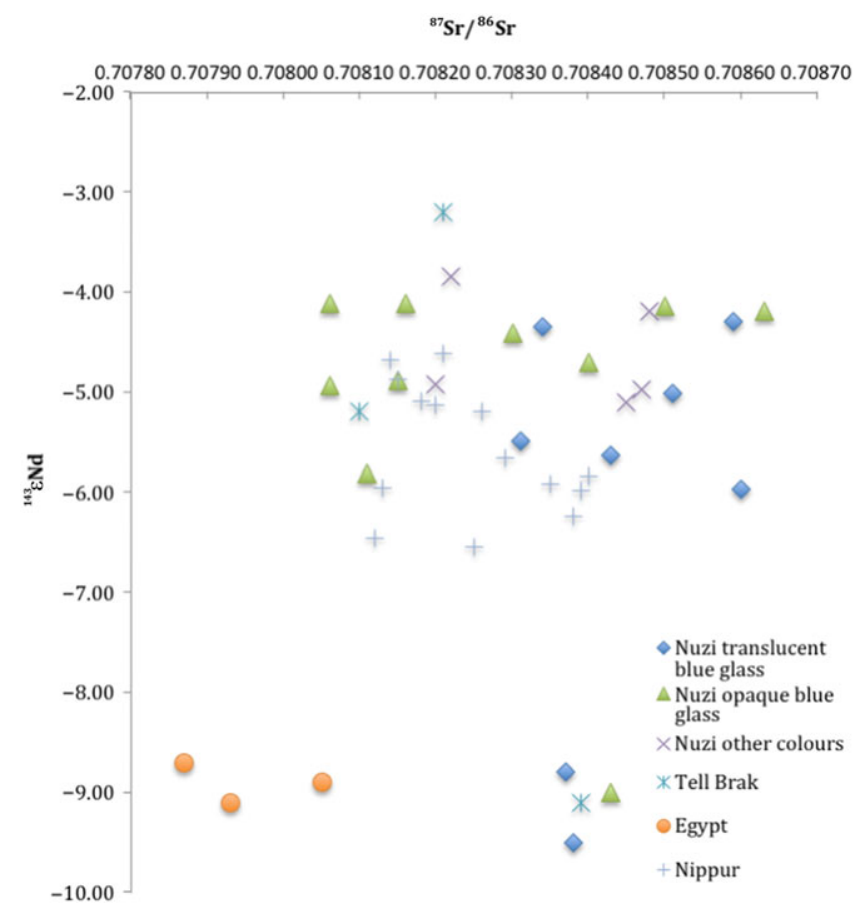

Figure 4 Sr and Nd isotopic data for Nuzi glasses plotted against data that have been published elsewhere for Malkata in Egypt, Tell Brak and Nippur (Degryse et al. 2010, 2015; Henderson et al. 2010). [Colour figure can be viewed at wileyonlinelibrary.com]

pattern is the trailing and marvering of contrasting colours on to the surface of the glass (Nicholson 1993; Nicholson and Henderson 2000). These trailed lines are often scored through to create characteristic surface decorations. If scored uniformly in one direction, a 'UUUU' pattern results, whereas if scored in two directions a 'VVVV' pattern is created. Petrie counted the different patterns on his fragments from the Amarna Palace Dumps and found that in these the UUUU pattern was dominant in Amarna glass vessels, making up 57\% for UUUU (13\% for VVVV and the rest for spirals, blotches and eyes, etc.: Petrie 1894). Amongst the glass vessel fragments at Nuzi, there are 133 examples of fragments of polychrome vessels, an estimated 30 or so vessels-some are very fragmentary. These have patterns and they show both UUUU and VVVV. However, careful examination of the UUUU patterns shows that they are significantly different in the way in which they are produced. The vertical scores of the different registers of the 'U's do not line up, as they would have to do if they were scored through together (see Fig. 5). This means that they could not have been created in the same way as the Egyptian examples. There are two possible ways in which they could have been created: either the registers were scored individually, or the pattern was laboriously laid on to the glass in a UUUU pattern, deliberately copying the single-scored vessels, but without using a scoring. Close examination of the glass, shown in Figure 5, shows that the latter is by far the most likely-the trails were laid on to the surface in a UUUU shape. A reasonable interpretation of this is that this patterning deliberately copies scored UUUU glasses as found in Egypt and elsewhere, but without an understanding of the scoring technique that was used to create these patterns. It is difficult to say how many of the 30 or so vessels that are perhaps represented here are this unusual UUUU 


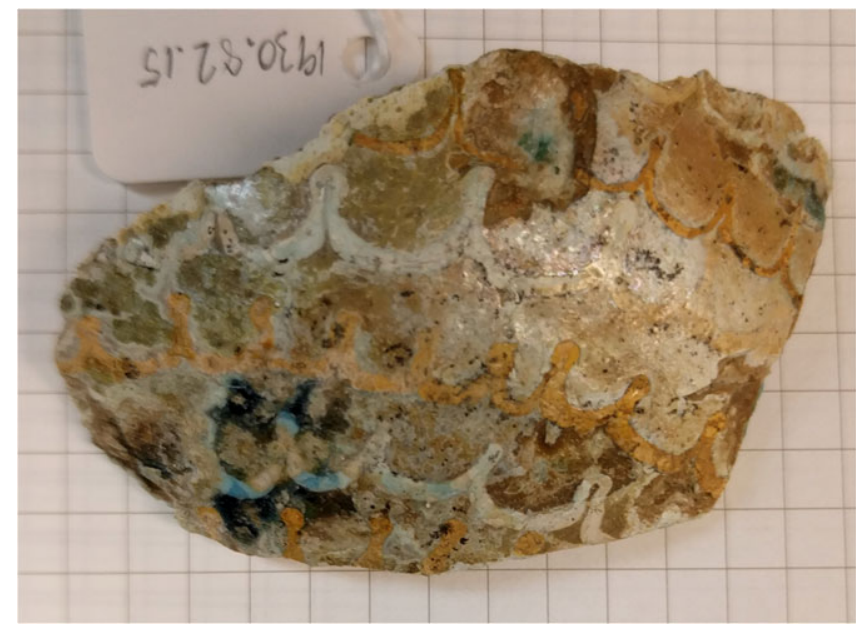

Figure 5 A fragment of Nuzi glass vessel 1930.82.15, showing UUUU patterns. The grid behind is of 5 mm squares. [Colour figure can be viewed at wileyonlinelibrary.com]

pattern as opposed to the 'Egyptian'-type VVVV or UUUU, but a reasonable suggestion would be that they represent the majority. Finds of scored together patterns represent only a small percentage.

\section{Compositional patterns}

The compositional results presented here and in Eremin et al. (in prep.) represent the greatest number of glass analyses ever published for Nuzi, and probably the largest in a single study for any LBA Near Eastern site. The volume of data allows patterns to be ascertained that have not been possible for smaller studies. As mentioned above, the main colourant for the glasses is copper. No significant amount of cobalt was found in any of the Nuzi blue beads, unlike Egyptian blue glasses, where cobalt is common. The opacity in the turquoise glasses is created by the addition of an antimony compound, giving an average of $2.0 \% \mathrm{Sb}_{2} \mathrm{O}_{5}$ in the opaque glasses. Antimony (without copper) is also used in the single white glass analysed. This is very similar to the colouring practices in Egyptian glasses.

This fairly limited and simple set of colourants is in contrast to that seen in Egyptian glasses, where very clear strategies are being used to create a whole range of colours. The Egyptian technology looks much more mature, with a regular technological strategy for each of the colours. The Nuzi glass has fewer colours and some colours-for example, green-seem potentially to be created almost accidentally, having, as it does, higher levels of iron. Table 3 shows the colouring strategies present in Amarna and in Nuzi, indicating contrasting strategies, with Nuzi having a much simpler range of options.

The major elements in the glasses are derived from the silica and flux components-quartz pebbles and plant ash, respectively, for most of these glasses. Quartz pebbles are usually thought to be a relatively pure form of silica, with few other elements in significant quantities, which means that the plant ash probably accounts for many of the other elements in the glass, including $\mathrm{Na}, \mathrm{Mg}, \mathrm{K}$ and $\mathrm{Ca}$, and perhaps Ti, $\mathrm{Al}$ and so on. The plot of $\mathrm{Al}_{2} \mathrm{O}_{3}$ against $\mathrm{Fe}_{2} \mathrm{O}_{3}$ (Fig. 3) shows that these elements are correlated in most of the glasses. Not only that, but the two correlations for the translucent blue glass and the opaque turquoise glasses are slightly, but significantly, 
Table 3 The distribution of the colouring technologies $(\times \times \times$, common; $\times \times$, present; $\times$, rare; $\circ$, not observed $)$

\begin{tabular}{llc}
\hline \hline Strategy & Egypt & Nuzi \\
\hline $\mathrm{Co}$ blue & $\times \times \times$ & 0 \\
$\mathrm{Cu}$ blue & $\times \times \times$ & $\times \times \times$ \\
$\mathrm{Co}+\mathrm{Cu}$ blue & $\times \times \times$ & 0 \\
$\mathrm{Cu}+\mathrm{Sb}$ turquoise & $\times \times \times$ & $\times \times \times$ \\
$\mathrm{Co}+\mathrm{Cu}+$ Sb opacified blue & $\times \times$ & 0 \\
$\mathrm{Co}+\mathrm{Sb}$ opacified blue & $\times \times \times$ & 0 \\
$\mathrm{Sb}$ white & $\times \times$ & {$[\times \times]^{*}$} \\
$\mathrm{~Pb}+\mathrm{Sb}$ yellow & $\times \times$ & $?[\times \times]^{*}$ \\
$\mathrm{Cu}+\mathrm{Pb}+\mathrm{Sb}$ green & $\times \times$ & 0 \\
$\mathrm{Mn}$ purple & $\times \times$ & 0 \\
$\mathrm{Cu}$ red & $\times$ & 0 \\
$\mathrm{Mn}$ black & $\times$ & 0 \\
Other blacks & $\times$ & $\times$ \\
Fe green & $\circ$ & $\times$ \\
\hline \hline
\end{tabular}

*Starr (1939) says that there were lots of yellow and white beads, but that the preservation was poor. These are not seen in the Harvard Collection. Could they be weathered blue beads?

different (Fig. 3). For the translucent glasses, the $\mathrm{Al}_{2} \mathrm{O}_{3} / \mathrm{Fe}_{2} \mathrm{O}_{3}$ ratio is about 0.4 , whereas for the opaque glasses it is around 0.75 . This suggests that two sources of raw materials might have been used for the two blues, or that the same raw materials were used, but the glass-making temperatures or processes were different, causing the elements to fractionate differently. Either way, the most likely reason for these differences is that the glasses were made in different workshops-one producing the translucent blue glasses, and the other the opaque glasses (turquoise and white).

Figure 2 also shows the lime component of the blue glasses. It is clear that the opaque glasses have, on average, a higher lime content than the translucent ones, at $9.0 \%$ compared to $6.0 \% \mathrm{CaO}$. This might be due to the different raw materials that were apparently being used: perhaps the plant ash used in the opaque glasses was not only slightly different in terms of alumina and iron (Fig. 3), but also had more lime. The other possibility is that the additional lime might have been added with the antimony opacifier. In Egyptian opaque blue glasses, the opacity is caused by precipitation in the glass on cooling of various types of calcium antimonate (Shortland 2002). However, in Egyptian glasses the calcium component of these opaque blue glasses is almost identical to that of the equivalent translucent blues, suggesting that no additional calcium was added to opaque glasses and that all calcium for the calcium antimonate particles was drawn from the glass itself. The Nuzi opaque glasses, with their higher lime contents, might well suggest that lime was being added with the antimony-a different practice to that seen in Egypt.

Therefore, the translucent and opaque blue glasses appear to have been made at different workshops, giving them different alumina and iron signatures, as well as potentially lime. The antimony contents also show an interesting pattern. Looking at the blue glasses as a whole, the antimony content is bimodal, with either very low antimony $\left(<0.3 \% \mathrm{Sb}_{2} \mathrm{O}_{5}\right)$ or high antimony $\left(>1.5 \% \mathrm{Sb}_{2} \mathrm{O}_{5}\right)$ (see Fig. 2). Thus, there is a clear split between the glasses that are opacified and those that are not. This is in complete contrast to Egyptian blue glasses, where the antimony content varies continuously across the whole range from zero to 3.2\% (Shortland and Eremin 
2006). This means that not only are the sources of the opacified and translucent blue glasses at Nuzi different, but those glasses are not subsequently mixed together. Thus, not only were they made in different places, but they were potentially worked in different places too, or the glasses were kept deliberately apart in one workshop. The Egyptian range of antimony values suggests that either varying amounts of antimony were being added to give just the right colour, or that there was much more mixing of the blue glasses.

\section{Isotopes}

The ${ }^{87} \mathrm{Sr} /{ }^{86} \mathrm{Sr}$ ratio varies from 0.7080 to 0.7086 (Fig. 4), clustering close to previously published values for the glass axes from Nippur (Walton et al. 2012) and other Near Eastern glasses (Degryse et al. 2010; Henderson et al. 2010). The translucent blue glasses are on average slightly higher than the opacified blue glasses by about 0.00015 , which might imply that the lime added to the opaque glasses to create the opacifier was slightly lower in ${ }^{87} \mathrm{Sr} /{ }^{86} \mathrm{Sr}$ than the glass as a whole, but the difference is too small to be able to say with any certainty.

As discussed in the results, the $\mathrm{Nd}$ data form two groups, one mostly from -4 to -7 , and a second smaller one at -8.5 to -9.5 . The smaller group has similar Nd values to Egyptian glass (although very different $\mathrm{Sr}$ isotopic ratios). This small group contains all the opaque glasses, very tentatively suggesting two silica sources for wherever this glass was produced.

\section{Who made the first glass?}

The question of where the first glass was made has been the subject of some debate. Some early papers put Egypt as the source of glass-making technology, presumably on the grounds of the widespread and colourful Egyptian glass (Moorey 1994, 190). Moorey states that 'pioneer scholars of glass history, like Bisa and Kissing, dismissed claims of Mesopotamia as an early producer' - the thought was that all the glass came from Egypt. Meissner (1920) was one of the first to argue that Mesopotamian glass was as old as Egyptian glass. However, with the discovery of Nuzi and further work on the earliest finds of glass there, by the 1980s at the latest, the emphasis had completely changed to a Near Eastern source for the glass-making innovation (Moorey 1994, 190). Why this has change has happened could be traced to several observations and assumptions, including the following:

1 finds of glass in early contexts in the Near East;

2 finds of early core-formed vessels in the Near East;

3 an early date for the very large amount of glass from Nuzi, with advanced polychromy;

4 the technical ability of the early Nuzi glassmakers;

5 Near Eastern glass-making texts;

6 Egyptian and other texts and scenes depicting gifts or tributes;

7 lead isotope analysis (LIA) of yellow glasses; and/or

8 innovations in metallurgy in the Caucasus.

Each of these has suggested the primacy of the Near East for the innovation of glass-making and each will now be considered in light of the most recent research.

There certainly have been random finds of early glass in the Near East, apparently dating back to the third millennium $\mathrm{BC}$ and assessed by Peltenburg (1987) and others. These are rare examples and many of them are of questionable context or date. There are also early finds in Egypt, equally questioned and problematic. However, it is unclear how these finds, classified as Stage I glass by Peltenburg, fit in, if at all, with the glass-making innovation that leads to widespread adoption of glass (Stage II glass). There is certainly no strong evidence here that 
the innovation occurred in the Near East. Given this, an attempt has been made to link the innovation not to the production of glass per se, but to the realization that glass is a new material and can be worked in new ways. The clearest marker for this is core-formed vessels, which explore the new material to its fullest. The finds of the first core-formed vessels might therefore indicate the source of glass-making. Unfortunately, the earliest vessels are again rare and often not clearly dated. There are significant finds of glass of this Stage II type at a number of sites in the Near East-for example, Tell Brak (Oates et al. 1997) and an early vessel (late 16th century BC) from Tell Atchana (Woolley 1955, 300, AT/39/225)—but as Moorey (1994, 193) says, 'the earliest evidence for [glass] vessels is not only sparse, but equivocal'. The early finds of glass and glass vessels are admirably presented in Moorey (1994), Barag (1970) and Peltenburg (1987), there is no need to repeat that here. Moorey sums it up, in the most recent proper assessment of this glass, arguing that 'in any attempt to elucidate the course of the innovation' of glass, the 'material evidence' from Egypt, Mesopotamia and the rest of the Near East is 'comparable', with none being 'more common' than the others (Moorey 1994, 193). Perhaps it might be suggested that there are a few more glass vessels with a secure early find site in the Near East than in Egypt; however, the evidence of primacy for the Near East is far from obvious.

What is clear is that the finds from Nuzi, representing as they do such a large amount of glass, were fundamentally important to placing the Near East as the source of glass-making (Moorey 1994). For example, Vandiver states that a 'fully fledged industry' of 'early fifteenth century date' existed at Nuzi (Vandiver 1983). Thus, the early date places Nuzi Stratum II glass out on its own, 100-150years before the Egyptian sites with large find of glass such as Amarna and Malkata. However, the early date for the Stratum II destruction level has now been revised (Stein 1989; Shortland 2012), and the Nuzi glass is now thought to be contemporaneous with that from Amarna, and therefore with the Egyptian glasses - thus Nuzi is no longer the earliest. From a material point of view this fits better, since Nuzi is now part of the wider glass innovation. However, the later date really removes perhaps the key reason for why the Near East was thought to be earlier in glassmaking. The careful re-examination of the Nuzi polychrome beads (Eremin et al. in prep.) and their categorization as Sasanian and later also removes a lot of the complexity and technological skill of the early Nuzi glass-working, and the majority of the advanced polychromy.

The next set of reasons for a Near Eastern lead on glass-making are based on textual evidence. First, there are texts found in the Library of Ashurbanipal at Nineveh that appear to give recipes for glass-making (Oppenheim 1970). Although the texts themselves are from the first millennium BC, they appear to be copies of much earlier LBA texts. Egypt has no glass-making texts, but this is related to the fact that the Egyptians did not write about such procedural matters - such things were not recorded. A lack of texts is therefore not evidence of a lack of glass production. More significant is the clear indication from other texts that Egyptian kings were asking for glass from the Near East (Shortland 2012). The earliest of these is an account in the Hall of the Annals at Karnak, which tells of the tribute given by Tuthmosis III (1479-1425 BC) following his victories in the Near East (Wreszinski 1923-40). Glass seems to be included in these lists, which are dated to the middle of the 15th century BC (Sherratt and Sherratt 1991). Later, the Amarna letters, dating to the third quarter of the 14th century BC, record the Egyptian king(s) asking for glass from vassal states in the Near East (Moran 1992). It is very possible, even probable, that both of these accounts represent the movement of some glass from the Near East into Egypt. However, do they represent the first glass? Two related lines of argument suggest that they do not. The first is that there are finds in Egypt in very good contexts, including datable tombs relating to Tuthmosis III (Lilyquist and Brill 1993). Included in this glass is the standard cobalt coloured, dark-blue glass that is widely thought to be made of Egyptian components in Egypt (Kaczmarczyk 1986; 
Shortland 2012). There is therefore good circumstantial evidence that Egypt was producing glass, and that this was following the same routine technology of the later Amarna and Malkata glass, at least as early as the 15th century BC, although exactly where is unclear. Second, the Hall of the Annals account of gifts given to the Temple at Karnak also directly mentions dark-blue glass, and specifically marks it with the king's cartouche-his name. It is tempting to see this as Egyptian dark-blue cobalt coloured glass given by the king to the Temple.

The final two points raised in favour of a Near Eastern source for glass-making are linked to the sources for some of the metal colourants. Lead isotope analysis has suggested that while most Egyptian yellow glasses coloured with lead antimonate derive their lead from local Egyptian sources, some of the earliest yellow glasses have another source, and this might be in the Near East (Lilyquist and Brill 1993; Shortland et al. 2000). This idea is based on few analyses and the actual source is unknown, but it is suggestive. The source of antimony is thought to be in the Caucasus (Shortland 2002), and all that can be stated definitively is that this is geographically closer to the Near East than Egypt. However, recent work on antimony isotopes (Degryse et al. 2015) has shown both that the antimony source for Near Eastern and Egyptian glasses is likely to be the same and that this it is consistent with a Caucasian antimony source. It is perfectly reasonable therefore to suggest that the early lead isotope results are the result of the lead and antimony traveling together, and that the Caucasian lead is replaced by local lead in Egypt in later glasses.

To counter these arguments for the Near East as the source of glass-making, it is possible to put some points forward in favour of Egypt as an alternative source. From the above discussion, it is clear that Egypt has a wider colour palette and seems to have more control of the use of colour. There are set recipes for most colours that are used repeatedly. Without doubt, the quality of Egyptian glass-working is higher-once again, the range of decoration on glass vessels and the control of the trailing and marvering technique seem to be better than in the Near East. Although there is obviously a question of differential preservation, the sheer number of glass vessels at Amarna in particular argues for a large and mature industry. Modern research therefore shows that the primacy of the Near East is based on very little evidence that still stands up to scrutiny. Egypt has an equal claim to be the site of first innovation. This paper proposes that at the moment the evidence is just not good enough to distinguish between the two.

\section{CONCLUSION}

WDS analysis indicates that the LBA glass from Nuzi seems to come from at least two production centres, one producing opaque and the other producing translucent blue glass. The other colours may be from either-unfortunately, too few have a good enough state of preservation to provide satisfactory analyses. The production of opaque glass involved adding lime and antimony to the batch, raising the lime content significantly, unlike the practice for contemporary opaque Egyptian glasses (although, for a different view, see Lahlil et al. 2010). The beads and vessels at Nuzi are overwhelmingly blue, suggesting more limited access to other colours. The decoration of some of the vessels superficially resembles trailing and marvering, but is made by a less complex method, suggestive of copying. In general, the glass at Nuzi appears less complex and developed than that at the contemporaneous Amarna. Interpretations of where the first glass was made have relied considerably on an early and very developed glass industry supplying Nuzi. This has given credence to the hypothesis that the Near East was the source of the glass-making innovation. The redating of Nuzi and re-examination of its glass, in addition to new considerations of the archaeological significance of the use of Near Eastern lead, show that this is no longer a strong conclusion. A better suggestion would be that either Egypt or the Near 
East could have been first. We can only hope that further work (and more fortuitous finds) will enable this debate to be resolved in the future.

\section{ACKNOWLEDGMENTS}

We gratefully acknowledge the help of Dr Joseph Green, Dr Adam Aja and the Harvard Semitic Museum for allowing us access to the collection and for their patience in answering questions and dealing with requests over many years. This project was part funded by an EPSRC CASE studentship joint with the Natural History Museum, London, which was a great help in much of the elemental analysis.

\section{REFERENCES}

Barag, D., 1970, Mesopotamian core-formed glass vessels, in Glass and glassmaking in ancient Mesopotamia: an edition of the cuneiform texts which contain instructions for glassmakers with a catalogue of surviving objects (eds. A. L. Oppenheim, R. H. Brill, D. Barag, and A. von Saldern), 129-99, Corning Museum of Glass, Corning, NY.

De Muynck, D., Huelga-Suarez, G., Van Heghe, L., Degryse, P., and Vanhaecke, F., 2009, Systematic evaluation of a strontium-specific extraction chromatographic resin for obtaining a purified Sr fraction with quantitative recovery from complex and Ca-rich matrices, Journal of Analytical Atomic Spectrometry, 24, 1498-510.

Degryse, P., Boyce, A., Erb-Satullo, N., Eremin, K., Kirk, S., Scott, B., Shortland, A., Schneider, J., and Walton, M., 2010, Isotopic discriminants between Late Bronze Age glasses from Egypt and the Near East, Archaeometry, 52, 380-8.

Degryse, P., Lobo, L., Shortland, A., Vanhaecke, F., Blomme, A., Painter, J., Gimeno, D., Eremin, K., Greene, J., Kirk, S., and Walton, M., 2015, Isotopic investigation into the raw materials of Late Bronze Age glass making, Journal of Archaeological Science, 62, 153-60.

Eremin, K., Kirk, S., Walton, M., Degryse, P., and Shortland, A. J., in prep., Re-examining the vitreous assemblage at Nuzi: the case for intrusion of late glass.

Ganio, M., Latruwe, K., Brems, D., Muchez, P., Vanhaecke, F., and Degryse, P., 2012, Sr-Nd isolation procedure for subsequent isotopic analysis using multi-collector ICP - mass spectrometry in the context of provenance studies on archaeological glass, Journal of Analytical Atomic Spectroscopy, 27, 1335-41.

Henderson, J., 1988, Electron microprobe analysis of mixed alkali glasses, Archaeometry, 30, 77-91.

Henderson, J., Evans, J., and Nikita, K., 2010, Isotopic evidence for the primary production, provenance and trade of Late Bronze Age glass in the Mediterranean, Mediterranean Archaeology, 10, 1-24.

Kaczmarczyk, A., 1986, The source of cobalt in ancient Egyptian pigments, in Proceedings of the 24th International Archaeometry Symposium (eds. J. S. Olin and M. J. Blackman), 369-76, Smithsonian Institution, Washington, DC.

Kaczmarczyk, A., and Hedges, R. E. M., 1983, Ancient Egyptian faience, Aris and Phillips, Warminster.

Keller, C. A., 1983, Problems of dating glass industries of the Egyptian New Kingdom: examples from Malkata and Lisht, Journal of Glass Studies, 25, 19-28.

Kirk, S., 2009, The vitreous materials from the 2nd millennium BC city of Nuzi: their preservation, technology and distribution, Ph.D. thesis, Cranfield University.

Lahlil, S., Biron, I., Cotte, M., Susini, J., and Menguy, N., 2010, Synthesis of calcium antimonate nano-crystals by the 18th Dynasty Egyptian glassmakers, Applied Physics A: Materials Science \& Processing, 98(1), 1-8.

Lilyquist, C., and Brill, R. H., 1993, Studies in ancient Egyptian glass, Metropolitan Museum of Art, New York.

Meissner, B., 1920, in Babylonien und Assyrien, vol. (ed. C. Winter), Vol. 1, Heidelberg.

Moorey, P. R. S., 1994, Ancient Mesopotamian materials and industries, Oxford University Press, Oxford.

Moran, W. L., 1992, The Amarna letters, The Johns Hopkins University Press, Baltimore, MD.

Nicholson, P. T., 1993, Ancient Egyptian faience and glass, Shire Publications, London.

Nicholson, P. T., 2007, Brilliant thngs for Akhenaten, Egypt Exploration Society, London.

Nicholson, P. T., and Henderson, J., 2000, Glass, in Ancient Egyptian materials and technology (eds. P. T. Nicholson and I. Shaw), 195-226, Cambridge University Press, Cambridge, UK.

Nicholson, P. T., Jackson, C. M., and Trott, K. M., 1997, The Ulu Burun glass ingots, cylindrical vessels and Egyptian glass, Journal of Egyptian Archaeology, 83, 143-53.

Oates, D., Oates, J., and McDonald, H., 1997, Excavations at Tell Brak, vol., in The Mitanni and Old Babylonian periods, Vol. 1, McDonald Institute for Archaeological Research, Cambridge UK/The British School of Archaeology in Iraq, London. 
Oppenheim, A. L., 1970, Glass and glass-making in ancient Mesopotamia, Corning Museum of Glass, Corning, NY.

Peltenburg, E. J., 1987, Early faience: recent studies, origins and relations with glass, in Early vitreous materials (eds. M. Bimson and I. C. Freestone), Occasional Papers 56, The British Museum, London.

Petrie, W. M. F., 1894, Tell el-Amarna, Methuen, London.

Pin, C., Briot, D., Bassin, C., and Poitrasson, F., 1994, Concomitant separation of strontium and samarium-neodymium for isotopic analysis in silicate samples, based on specific extraction chromatography, Analytica Chimica Acta, 298, 209-17.

Pusch, E., and Rehren, T. H., 2007, Rubinglass für den Pharao: Hochtemperatur-Technologie in der Ramses-Stadt, Gerstenburg, Hildesheim.

Sherratt, A., and Sherratt, S., 1991, From luxuries to commodities: the nature of Mediterranean Bronze Age trading systems, in Bronze Age trade in the Mediterranean (ed. N. H. Gale), 351-86, Paul Åströms Förlag, Jonsered.

Shortland, A. J., 2002, The use and origin of antimonate colorants in early Egyptian glass, Archaeometry, 44, 517-30.

Shortland, A. J., 2012, Lapis lazuli from the kiln: glass and glassmaking in the Late Bronze Age, Leuven University Press, Leuven.

Shortland, A. J., and Eremin, K., 2006, The analysis of second millennium glass from Egypt and Mesopotamia, part 1: new WDS analyses, Archaeometry, 48, 581-605.

Shortland, A. J., Nicholson, P. T., and Jackson, C. M., 2000, Lead isotopic analysis of 18th Dynasty Egyptian eyepaints and lead antimonate colorants, Archaeometry, 42, 153-9.

Shortland, A., Eremin, K., Kirk, S., and Armstrong, J., 2008, Reassessing Bronze Age manufacturing technologies at Nuzi, in Materials issues in art and archaeology VIII: symposium held November 26-28, 2007, Boston, Massachusetts, USA (eds. P. B. Vandiver, B. McCarthy, R. H. Tykot, J. L. Ruvalcaba-Sil, and F. Casadio), 217-32, Materials Research Society, Warrendale, PA.

Starr, R. F. S., 1939, Nuzi: report on the excavations at Yorgan Tepa, Kirkuk, Iraq, Harvard University Press, Cambridge, MA.

Stein, D. L., 1989, A reappraisal of the 'Saustatar letter' from Nuzi, Zeitschrift für Assyriologie und Vorderasiatische Archäologie, 79, 36-60.

Turner, W. E. S., 1954, Studies in ancient glasses and glass making processes. Part I. Crucibles and melting temperatures employed in ancient Egypt at about 1370 BC, Journal of the Society of Glass Technology, 38, 436T-444T.

Turner, W. E. S., 1956, Studies in ancient glasses and glass making processes. Part III. The chronology of glass making constituents, Journal of the Society of Glass Technology, 40, 39-52.

Vandiver, P., 1983, Glass technology at the mid-second-millennium BC Hurrian site of Nuzi, Journal of Glass Studies, 25, 239-47.

Walton, M., Eremin, K., Shortland, A., Degryse, P., and Kirk, S., 2012, Analysis of Late Bronze Age glass axes from Nippur-a new cobalt colourant, Archaeometry, 54, 835-52.

Woolley, L., 1955, Alalakh: an account of the excavations at Tell Atchana in the Hatay, 1937-1949, The Society of Antiquaries, Oxford.

Wreszinski, W., 1923-40, Atlas zur altaegyptischen Kulturgeschichte J. C. Hinrichs, Leipzig. 